\title{
Comparative Efficiency Analysis of Portuguese Bank Branches
}

Maria Conceição A. Silva Portela* and Emmanuel Thanassoulis**

July 8, 2005

* Universidade Católica Portuguesa

Centro Regional do Porto

R. Diogo Botelho, 1327, 4169-005 Porto

Portugal

csilva@porto.ucp.pt

** Aston Business School

Aston Triangle, B4 7ET Birmingham

U.K.

e.thanassoulis@aston.ac.uk 


\begin{abstract}
The advent of Internet banking and phone banking is changing the role of bank branches from a predominantly transaction-based one to a sales-oriented role. This paper reports on an assessment of the branches of a Portuguese bank in terms of their performance in their new roles in three different areas: Their efficiency in fostering the use of new transaction channels, their efficiency in increasing sales and their customer base, and their efficiency in generating profits. Service quality is also a major issue in service organisations like bank branches, and therefore we analyse the way this dimension of performance has been accounted for in the literature and take it into account in our empirical application. We have used Data Envelopment Analysis (DEA) for the different performance assessments, but we depart from traditional DEA models in some cases. Performance comparisons on each dimension allowed us to identify benchmark bank branches and also problematic bank branches. In addition, we found positive links between operational and profit efficiency and also between transactional and operational efficiency. Service quality is positively related with operational and profit efficiency.
\end{abstract}

Keywords: Banking, Efficiency, Service quality, Profitability 


\section{Introduction}

The emergence of new forms of banking presents a challenge to the predominance of bank branches as the main avenue of providing financial services. These alternative ways of banking include, phone banking, internet banking and automatic banking (through automatic teller machines - ATMs). The increasing use of alternative banking channels (ECB, 1999a) is clearly changing the traditional way of understanding and undertaking banking activities.

At the bank branch level the emergence of new distribution channels might only partly be able to reduce the importance of bank branches as distribution means of financial services, especially due to the increase in personal-advice intensive banking activities that is being undertaken (ECB, 1999b). Bank branches have been shifting from operating services to consulting (ECB, 1999b), i.e., they are placing less importance on the delivery of transactional services and more importance on exploiting the potential of branch networks as selling outlets for financial services (e.g. Drake and Howcroft, 1995; Howcroft and Beckett, 1993; Howcroft, 1992). In this sense, new distribution channels can be regarded as advantageous to bank branches, since they can place more emphasis on value-added activities (sales related) leaving basic transactions to be performed on other means of distribution. For the bank as a whole this represents a cost advantage, since general operations performed on alternative means of distribution are cheaper than when performed by bank branches' personnel.

Existing studies on bank branches efficiency do not in general account for the changing role of bank branches. Most of these studies analyse efficiency of bank branches from a production perspective $^{1}$ (in contrast with a intermediation perspective (see e.g. Colwell and Davis, 1992)), where bank branches are seen as production units using a set of resources

\footnotetext{
${ }^{1}$ See e.g. Sherman and Gold (1985); Parkan (1987); Vassiloglou and Giokas (1990); Giokas (1991); Tulkens (1993); Drake and Howcroft (1994); Sherman and Ladino (1995); Athanassopoulos (1997); Schaffnit et al. (1997); Camanho and Dyson (1999); Zenios et al. (1999); Soteriou and Zenios (1999); Golany and Storbeck (1999); Avkiran (1999); Athanassopoulos et al. (2000); Athanassopoulos and Giokas (2000); Hartman et al. (2001).
} 
(mostly staff, space, computers and supply costs) to produce a number of services (mostly measured through the number of transactions at a bank branch and/or the number of various accounts). Albeit important, a production perspective fails to reflect other important dimensions of bank branches. In order to try to circumvent this problem some authors have used together various perspectives of bank branches activities (see e.g. Athanassopoulos (1997), Athanassopoulos et al. (2000), Berger et al. (1997), etc.). Most of these studies do not account, however, for the new role of bank branches toward selling nor link this new role with the growth of alternative/competitive ways of providing banking services like the internet, phone banking and ATMs. In addition, the role of sales as the most important operational output of bank branches has not been acknowledged in older studies, but only recently by Cook et al. (2000) and Cook and Hababou (2001), who take explicitly into account the new role of bank branches by distinguishing two types of activities that happen in bank branches: transactions (or service) and sales.

The purpose of the present study is to specify suitable efficiency measures that take into account sales activities of bank branches, and transactional activities that should be performed on alternative distribution channels. Apart from these two dimensions of bank branches activities we also consider their profit. Bank branches are for-profit organisations and therefore an analysis of their performance should also account for this dimension. The use of profit efficiency measures may also be seen as a way of incorporating a service quality dimension into the analysis, since accounting both for costs and revenues may avoid classifying a higher quality bank or bank branch as cost inefficient just because it produced higher quality (and therefore generated more revenues) at the expense of higher costs (Berger et al., 1993). Service quality is of utmost importance in analysing the performance of bank branches, since their survival depends on the service quality levels they provide. We consider this performance dimension a posteriori for reasons that will be outlined afterwards. 
The paper is structured as follows. In the next section a set of efficiency measures that we developed to analyse the overall performance of bank branches is put forth. In section 3 these measures are applied to a sample of Portuguese bank branches and results are crosscompared. In section 4 our results are compared with prior views of managers of the bank under analysis, and section 5 concludes this paper.

\section{Measuring the Performance of Bank Branches}

Many managers believe that the growing use of new distribution channels does not constitute a threat to the survival of bank branches, at least not in the short run. This fact is, instead, taken as an opportunity to move non-value-added transactions to these new channels, leaving branches with more time to devote to value-added activities. Seeing new means of distribution as an opportunity for increasing profits, the bank under analysis charged their branches with the responsibility for motivating customers to use alternative channels. As a consequence, the main objectives that bank managers ask their branches to pursue are:

- To foster an effective use of new distribution channels so that branch personnel can use their time in value-added activities;

- To increase sales and the customer base of the branch, while serving the clients that visit the branch with high service quality levels;

- To manage the product mix in a way that generates high profitability, without reducing service quality associated with any product.

Given these objectives it is important to develop corresponding performance measures to assess the extent to which each of these objectives is being achieved by bank branches. For this purpose, we developed three performance measures: transactional, operational, and 
profit, corresponding to each of the objectives stated above. The assessment of performance on the three dimensions is centered at the bank branch and therefore we used DEA to compare bank branches on each dimension (for details on this methodology see e.g. Cooper et al. (2000) and Thanassoulis (2001)). Note that as banking activities are increasingly performed through a mix of distribution channels it is difficult to credit a particular channel for a particular sale (in general more than one channel is involved in each sale). The bank branch is, however, for the Portuguese market still the preferred distribution channel and therefore it makes sense to focus our analysis on this channel. We opted to use DEA in this analysis primarily for two reasons: Firstly, as will be seen below, the assessments involve setting multiple inputs against multiple outputs and DEA is one of the assessment methods that can most easily handle such contexts. Secondly, we avoid the need to make prior assumptions as to the functional form linking inputs and outputs as would be needed if we use a parametric distance function approach. There is the difficulty that DEA cannot account for random noise in the data but this is less important when we are looking for general indications rather than definitive numerical measures of performance of bank branches.

For measuring operational and profit efficiency some methodological developments were needed, and therefore we developed our own models to measure these efficiencies. In the next sections we define each efficiency measure and point out the main issues that were raised in their development. We do not make an exhaustive presentation of mathematical models since the aim of this paper is to present empirical results rather than to dwell on methodological issues (for details the reader is referred to Portela (2003)).

\subsection{Transactional Efficiency}

Transactional efficiency is defined as the extent to which a bank branch moves general transactions away from the branch to alternative means of distribution. Note that our 
interest here is not related to the efficiency of new distribution channels as a selling outlet for the bank as a whole (DEA would not probably be the right tool for performing such an analysis). Our focus is on the role of bank branches - our unit of analysis - in motivating their customers to use new distribution channels.

The input-output variables used in this assessment are shown in Table 1. These variables are available monthly for the period from January 2002 to September 2002. The chosen

Table 1: Inputs and Outputs used to assess transactional efficiency in month t

\begin{tabular}{l|r}
\hline Inputs & Outputs \\
\hline 1. Number ETMs (ATMs + CATs) (t) & 1. N. New registrations for internet use (t) \\
2. Rent (t) & 2. N. Transactions in CATs (t) \\
3. N. Clients not registered (t-1) & 3.N. Deposits in ETMs (t) \\
\hline
\end{tabular}

variables differ from those we considered ideal, since the bank could not supply some data (like transactions on each distribution channel made by a branch's own clients, or socioeconomic characteristics of clients that affect their propensity to use new channels). On the input side of the transactional efficiency assessment we try to account for the resources that allow a bank branch to foster the use of alternative distribution channels. The number of ETM's is the sum of automatic teller machines (ATM's) and cheque dispenser machines (CAT's). The variable 'rent' is a surrogate for the location and size of the bank branch (this variable is used internally by the bank and does not depend on the bank owning the branch or not), and the variable 'number of clients not registered' links with the output 'number of registrations for internet use' (which basically measures each month how many customers registered that month to use internet). The other outputs used in the transactional efficiency assessment are intended to capture the degree of usage of ETMs. As we were interested in the usage of this distribution channel by branch's clients we considered only those transactions whose probability of being done by a branch client is higher. This is the case of deposits in ETM's, and all transactions in CAT's. The number of ETMs at a branch and the notional 
rent for the branch jointly capture not only the size of the client base of the branch but also their quality so that in general the higher the levels of rent and ETMs the larger the levels management would expect, all else being equal, on outputs 2 and 3 in Table 1.

Note that in the transactional efficiency assessment we focus on branches' clients only, and therefore neglect the effort of branches' personnel in motivating clients that are not their own in using alternative distribution channels. This is a necessary simplification for performing the analysis at the branch level. This clearly represents a limitation of the assessment, as some branches located in high passing trade zones may have more transactions performed by non-branch clients than by their own clients. This fact may under-estimate the efforts of a branch in motivating customers (irrespective of the branch in which they are clients) to use alternative distribution channels.

Note that we have not included manpower as part of the input set in Table 1 in order to capture any inefficiency in the use of new channels attributable to the branch having deployed an inappropriate staff complement. Otherwise a branch could set a low staff complement against low usages of new channels and still appear efficient. Yet there may have been potential to raise further the use of new channels if more staff had been hired.

The DEA model used to measure transactional efficiency each month was a variable returns to scale (VRS) output oriented model (Banker et al., 1984). We used VRS because it is a less restrictive assumption than CRS. We have no a priori reason to believe that for efficient branches outputs and inputs are proportional. This was supported by statistical tests (see e.g. Banker, 1996) that showed CRS and VRS efficiencies cannot be assumed to come from the same distribution. 


\subsection{Operational Efficiency}

Operational efficiency is related to all types of operations that go on in a bank branch. It accounts especially for value-added operations (sales related) and therefore this measure is linked with the previously defined transactional efficiency. That is, the more transactions a bank branch moves to alternative distribution channels the more time branch staff will have to perform value-added activities, and therefore it is likely that the operational efficiency is higher for those bank branches showing higher transactional efficiency.

The operational efficiency assessment considers data from March 2001 to September 2002. The input-output set used in this assessment is shown in Table 2, where $(t)$ denotes time period and the Greek $\Delta$ denotes change in values between the start and the end of period $t$.

Table 2: Inputs and Outputs used to assess operational efficiency in month t

\begin{tabular}{l|r}
\hline Inputs & Outputs \\
\hline 1. Number Staff (t) & 1. $\Delta$ Number of Clients (t) \\
2. Rent (t) & 2. $\Delta$ Value Current Accounts (t) \\
& 3. $\Delta$ Value Other Resources (t) \\
& 4. $\Delta$ Value Titles Deposited (t) \\
& 5. $\Delta$ Value Credit by Bank (t) \\
& 6. $\Delta$ Value Credit by Associates (t) \\
& 7. Number Transactions (t) \\
\hline
\end{tabular}

The inputs we have used reflect the main operational resource of bank branches (staff) ${ }^{2}$ and its environmental conditions (rent). Note that we present in Table 2 a reduced set of variables because of data limitations. Had suitable data been available we would have liked to also consider in the operational efficiency assessment inputs relating to the market potential the branch is in since this is a factor potentially affecting its ability to increase customers and the value of the various products it sells.

\footnotetext{
${ }^{2}$ The argument stated before for not including personnel in the transactional efficiency assessment does not apply in Table 2 where staff are an input, because here we want to capture the efficiency of staff deployed in performing transactions and sales while in Table 1 we want to capture the efficiency of the branch in converting the potential for clients to switch to new channels.
} 
The outputs in Table 2 are intended to reflect the main operational objectives of bank branches; (i) to increase the customer base (reflected in the output $\boldsymbol{\Delta}$ number of clients), (ii) to increase sales of the various products the branch has to offer (reflected in outputs 2 to $6^{3}$ ), and (iii) to serve clients (reflected in the output number of general transactions). As the bank could not supply us with sales values we used a surrogate for sales given by the difference between values in month $t$ and $t-1$. This resulted in some outputs being negative. In order to apply DEA to negative data we developed a model called Range Directional Model (RDM) (see Portela et al., 2004) that is based on the directional distance model of Chambers et al. $(1996,1998)$. The model used was output oriented but the output 'number of transactions' was considered non-discretionary ${ }^{4}$, i.e., an output that the bank branch does not want to improve. This is consistent with the new role of bank branches that focus especially on selling and prefer general transactions to be performed on alternative distribution channels. The RDM output model is presented in appendix A.

Note that the specification of outputs as the difference between values in period $t$ and values in period $t-1$, results in a DEA model that is equivalent to another where we consider the absolute value in $t-1$ on the input side and the absolute value in $t$ on the output side, with the additional constraint that the weights attributed to pairs of inputs and outputs, related in this way, should be equal. More details on this point can be found in Portela (2003).

\footnotetext{
${ }^{3}$ Some of these outputs deserve some explanations. Other resources include term deposit accounts, emigrant accounts, investment funds, savings insurance, etc. We consider here two broad classes of credit (as classified by the bank): credit by the bank includes consumer's credit, cards credit, overdrafts, etc.; and credit by associates includes factoring and leasing, which is provided by associate companies inside the same financial group.

${ }^{4}$ The non-discretionary of transactions was treated in the RDM model according to the approach of Banker and Morey (1986).
} 


\subsection{Profit Efficiency}

The profit efficiency measure is intended to capture the extent to which a bank branch is profit maximising. Note that our interest here is not simply to calculate what the profit (understood as an accounting concept) was, but to compare the potential for profit maximisation of bank branches.

The profit efficiency assessment uses data from March 2001 to September 2002. The input-output variables used in this assessment are shown in Table 3. These variables are

Table 3: Inputs and Outputs used to assess profit efficiency in month $t$

\begin{tabular}{l|r}
\hline Inputs & Outputs \\
\hline 1. Number of Staff (t) & 1. Value Current Accounts (t) \\
2. Supply costs (t) & 2. Value Other Resources (t) \\
& 3. Value Credit Over Bank (t) \\
& 4. Value Credit Associates (t) \\
\hline
\end{tabular}

consistent with the intermediation approach of bank branches' activities as discussed before (for details see Portela and Thanassoulis, 2005). Note that an important output that is not included in our analysis is non-interest revenue. This is an increasingly important output since competitive pressures on bank profits have led bank branches to create other sources of revenues through commissions and fees. Unfortunately the bank was not able to supply this output and therefore we could not use it in our analysis.

Apart from the 'quantity' variables specified in Table 3, price data were also available for staff (average salaries) and for all outputs. We used the variables in Table 3 to compute two types of efficiency: technical and overall profit efficiency. For the technical profit efficiency measurement we used the variables as specified in Table 3. For calculating overall profit efficiency we used the 'quantity' data specified in Table 3 plus price information. Note that output prices used were net interest rates, meaning that when outputs were multiplied by prices the result was net interest revenue (interest revenue - interest cost) rather than simply 
interest revenue.

The results we report in this paper concerning profit efficiency do not consider factor prices. That is, we report on values of technical profit efficiency and not overall profit efficiency. The reader is referred to Portela and Thanassoulis (2005) for details on the assessment of overall profit efficiency and its decomposition into technical and allocative efficiency. The technical profit efficiency assessment undertaken was based on non-oriented DEA models where at the same time outputs could increase and inputs could decrease ${ }^{5}$. The model used was based on a geometric distance function (GDF) detailed in Portela and Thanassoulis (2005). In Appendix B we show the basic models within the GDF procedure including the model used in this paper to calculate technical profit efficiency.

\section{Main Results}

Monthly efficiency results (including efficiency scores, target levels and peers) were produced for each performance dimension for a total of 57 bank branches. This type of information is too detailed to be presented in this paper, where our aim is to show general results on each performance dimension and the links between them. In addition, for the bank as a whole more important than having monthly detailed efficiency results for each branch, it is to know those bank branches that showed a consistently efficient or inefficient behaviour over the period of analysis, and to have an overall picture of the performance of bank branches in each dimension. In the sub-sections that follow we compare pairwise results from the three efficiency assessments. For this purpose we calculated, for each branch, average efficiency scores (transactional, operational or profit) for the overall period of analysis (this is January

\footnotetext{
${ }^{5}$ This orientation was chosen so that the resulting measure reflected profit efficiency. Otherwise, if an input orientation was chosen the resulting measure would reflect cost efficiency and if an output orientation was chosen the resulting measure would reflect revenue efficiency.
} 
2002 to September 2002 for transactional efficiency, and March 2001 to September 2002 for the operational and profit assessments).

\subsection{Operational Efficiency Vs Profit Efficiency}

Average efficiency scores obtained from the operational and profit efficiency assessments are plotted in Figure $1^{6}$. We choose in this Figure a threshold of $90 \%$ for good efficiency and

Figure 1: Profit Efficiency and Operational Efficiency

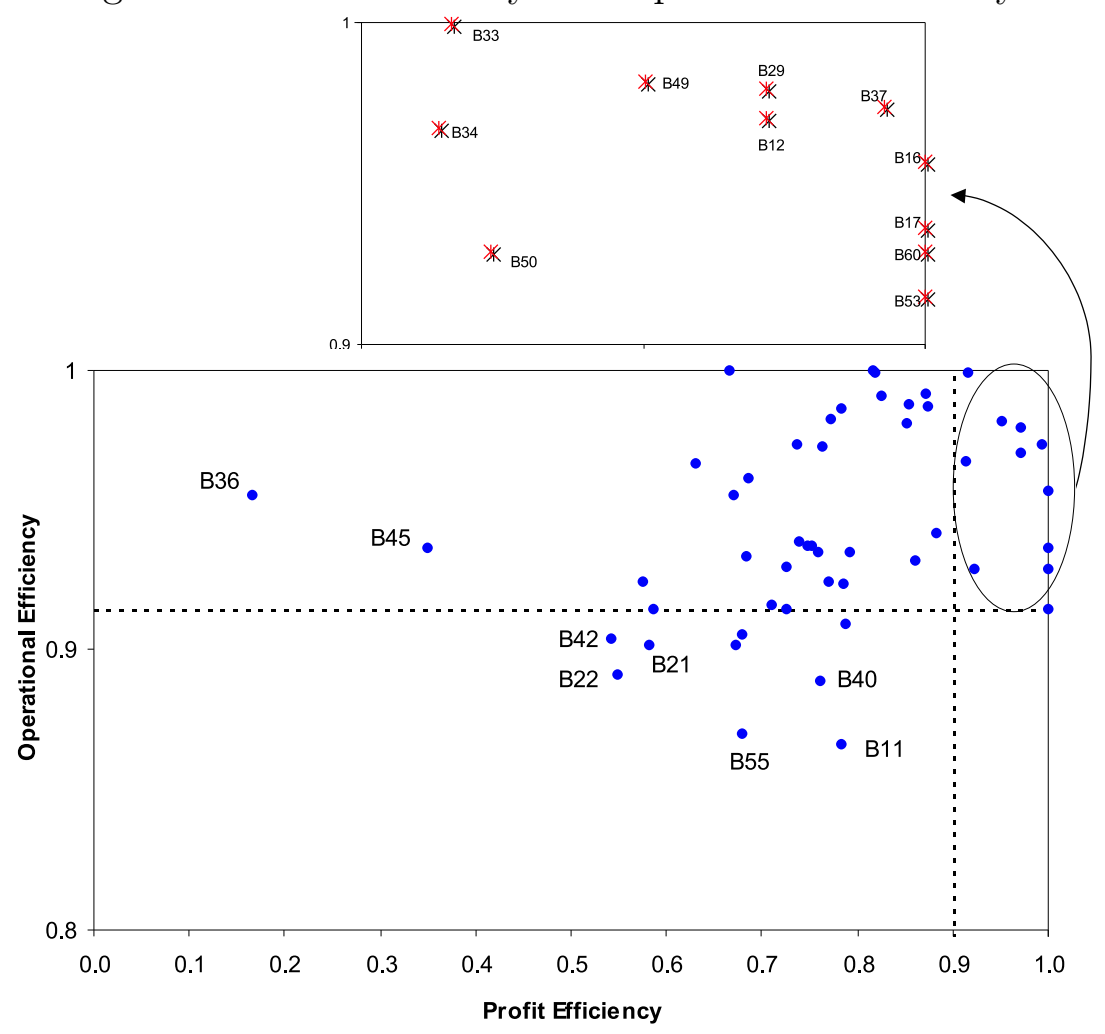

consider that below this value branches have scope to improve performance. This threshold is arbitrary since the managerial implications of drawing such a graph do not really depend on the chosen threshold, but on the number of units close to the ideal performance $(1,1)$. Note that different threshold may be justified by different magnitudes of efficiency/inefficiency.

\footnotetext{
${ }^{6}$ These averages are computed based on independent efficiency assessments made each month. In the whole study from where the results in this paper are extracted (Portela, 2003), an analysis of not only efficiency change but also technological change (i.e. changes in the technological frontier) was performed. We do not detail on this type of results in this paper for sake of brevity.
} 
Bank Branches with good performance both in profit and operational terms can be classified as 'stars' (Boussofiane et al., 1991) and they represent benchmarks to be emulated by inefficient branches. Problematic branches are those that have low operational and low profit technical efficiency. Special attention should be paid to these branches and action is needed to diagnose their problems and to improve their performance.

Bank branches with good profit efficiency and low operational efficiency do not exist in our data set (see Figure 1). The absence of bank branches in this quadrant is in line with common sense, since branches with low operating efficiency (i.e. showing a poor performance in selling and attracting new customers) are not likely to be efficient in generating profits. Our results therefore are not surprising.

The correlation coefficient between average profit and average operational efficiency is 0.3. This is not a very high correlation coefficient but it is statistically significant at the $5 \%$ level. This means that, in a limited way, higher operational efficiency tends to be related with higher profit efficiency as can be seen in Figure 1.

A more detailed analysis of star branches and problematic branches in Figure 1 can be undertaken by analysing differences in their input/output levels. In the radar graphs shown in Figure 2 we can compare the operational and profit efficiency average input/output levels of star branches with those of low operational and low profit branches (LOLP). In the radar

Figure 2: Star Vs LOLP branches

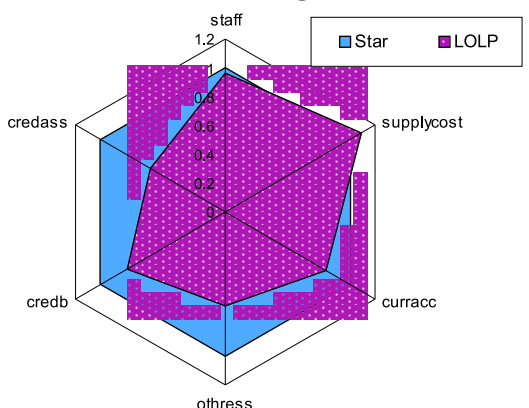

Profit Efficiency Variables

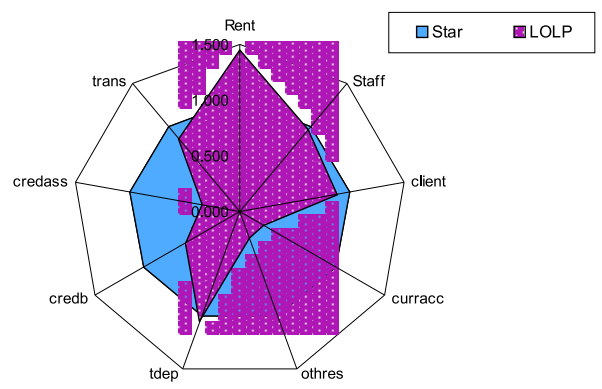

Operational Efficiency Variables 
graph on the left we can see that LOLP branches use on average about the same staff and supply costs as star branches to produce much less of all the outputs considered in the profit assessment. Differences are even more marked for the case of the inputs and outputs used to measure operational efficiency (radar graph on the right). Note that in the above radar graphs values for each variable are normalised by the values observed for star branches.

The analysis of radar graphs such as those shown in Figure 2 provides useful managerial information to bank managers since they can easily identify where improvement should be sought with priority. For example, when the operational objective of growth is considered, we can see that LOLP branches should focus on improving growth of current accounts, other resources and credit associates. In terms of titles deposited and clients growth these branches perform on average similarly to star branches and therefore these areas do not give particular cause for concern. By achieving growth in the critical areas LOLP bank branches will achieve higher volumes of credit and other resources that will contribute also to improve their performance in the profit efficiency assessment.

\subsection{Operational Efficiency Vs Transactional Efficiency}

Comparing profit and operational efficiency with transactional efficiency shows a positive and statistically significant correlation between transactional efficiency and operational efficiency, but a non-significant correlation between profit and transactional efficiency. In Figure 3 we show the matrix that cross compares operational and transactional efficiency. The values in this figure are average efficiency scores from January 2002 to September 2002.

In the same way as before we can see some bank branches in the star quadrant showing high operational and high transactional efficiency. In particular, branches B4 and B54 have $100 \%$ efficiency in both dimensions and this makes them suitable role models for emulation by other branches. There are virtually no branches in the low operational-high transactional 
Figure 3: Transactional Efficiency and Operational Efficiency

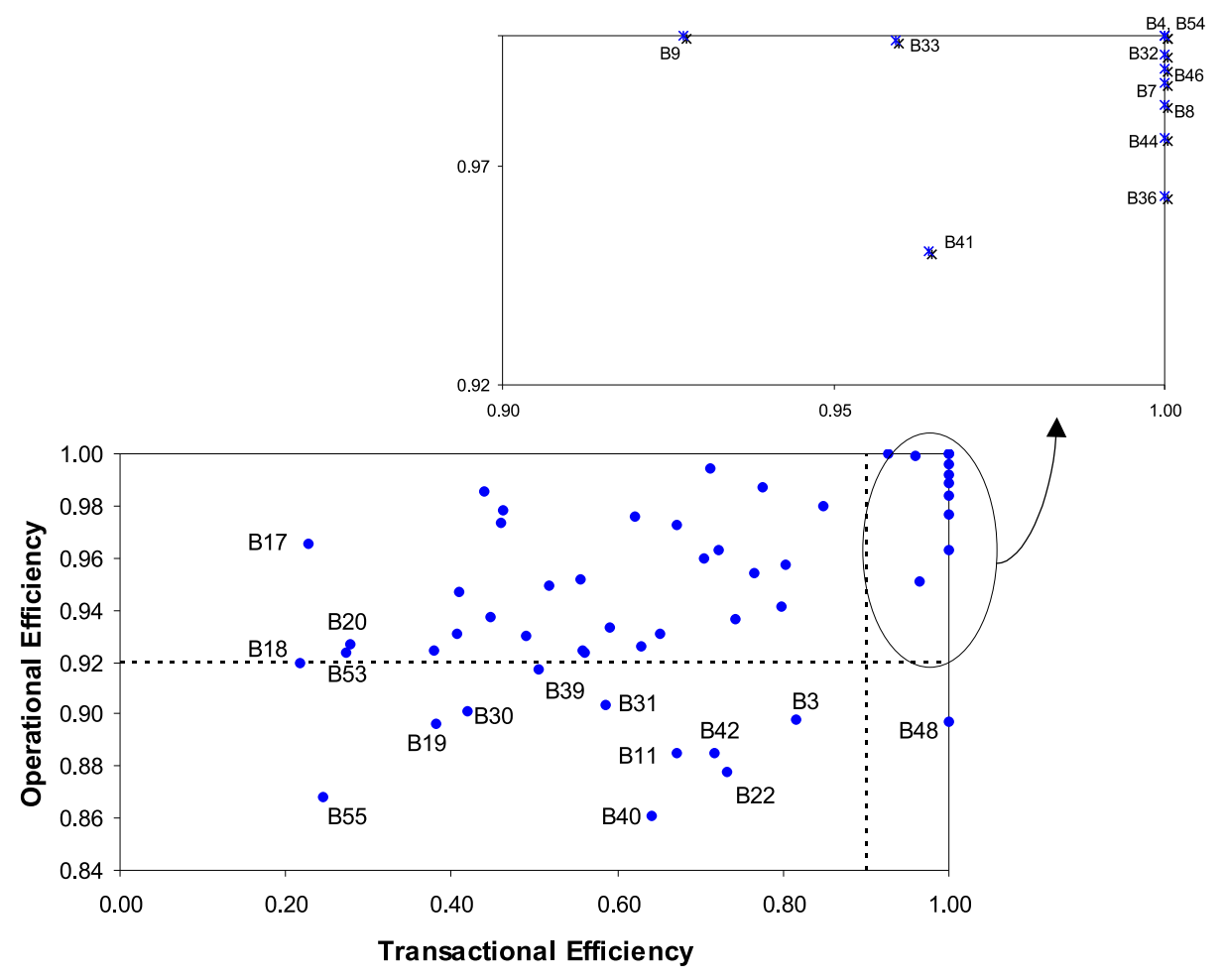

quadrant in Figure 3, meaning that branches that are good performers in moving transactions to other means of distribution are, in general, also good performers in operational activities that are not transactions related. Indeed the correlation coefficient between these two performance dimensions is 0.46 and this value is statistically significant at the $1 \%$ level even if relatively low. This fact confirms our initial hypothesis that moving transactions to alternative means of distribution gives branch staff more time to dedicate to value added activities that leads to increasing sales and the customer base of the bank branch (which are outputs of the operational efficiency assessment).

\subsection{Link between Efficiency and Service Quality}

Service quality is an important aspect to be accounted for in an efficiency analysis of service organisations like bank branches. For this type of organisations we can distinguish between two concepts of efficiency: internal efficiency, related to the efficiency by which outputs 
can be produced through a given amount of inputs, and external efficiency, related to the efficiency by which perceived service quality is produced through a given amount of inputs (Grönroos, 2000). While in manufacturing organisations it may be easier to separate internal and external efficiency, in service organisations these two measures of efficiency are entangled. That is, the introduction of more "cost effective production resources and processes does not necessarily lead to better economic results" (Grönroos, 2000, p. 206). This is because internal efficiency is related to cost efficiency (cost savings can be achieved by improving internal efficiency) but external efficiency is related to revenue efficiency (low service quality may result in a loss of customers and revenues) (see also Howcroft, 1991; Thanassoulis et al., 1995). A way to account for both internal and external efficiency is through a profit analysis since the former is related to costs and the latter to revenues (see also Berger et al. (1993), who argue that profit efficiency can account for differences in quality between banks) ${ }^{7}$.

Service quality has been considered in some DEA bank branches studies either through the inclusion of quality variables into the efficiency analysis (Parkan, 1987; Golany and Storbeck, 1999; Athanassopoulos, 2000), or by post-hoc analysis where a service quality index is compared to efficiency measure(s) (Schaffnit et al., 1997; Athanassopoulos, 1997). In this study we adopt this latter perspective, though we consider that service quality is intrinsical to efficiency assessments of service organisations even if no direct service quality variables are present in the assessment model, provided other variables in the model capture the impact of service quality. This is so in our case where variables such as change in client or asset base (in the operational efficiency assessment) and value of various assets (in the profit efficiency assessment) do capture the impact of service quality. The levels of these

\footnotetext{
${ }^{7}$ Note that profit as defined in accounting terms may be considered a second best tool to measure the firm's long term performance, given the lagging effect between changes in quality and the corresponding changes in profit. This lagging effect makes a static analysis of profit efficiency of reduced importance and suggests this efficiency should be measured over time so that quality differences may be captured. In our empirical application we use a 18 month period and so our analysis considers profit over an extended period allowing many lagging effects to be captured.
} 
variables would drop if service quality is poor.

In our empirical study the service quality variable we have is an index based on monthly questionnaires sent to branch customers. In Figure 4 we show the scatter plot of operational efficiency and service quality. The data on service quality relates to September 2002, meaning that it is an average of SQ indexes from September 2001 to September 2002. The average values calculated for operational and profit efficiency measures also consider this year period. Note that the threshold that we consider for the service quality index is 0.8 , because it seemed

Figure 4: Operational Efficiency Vs Service Quality

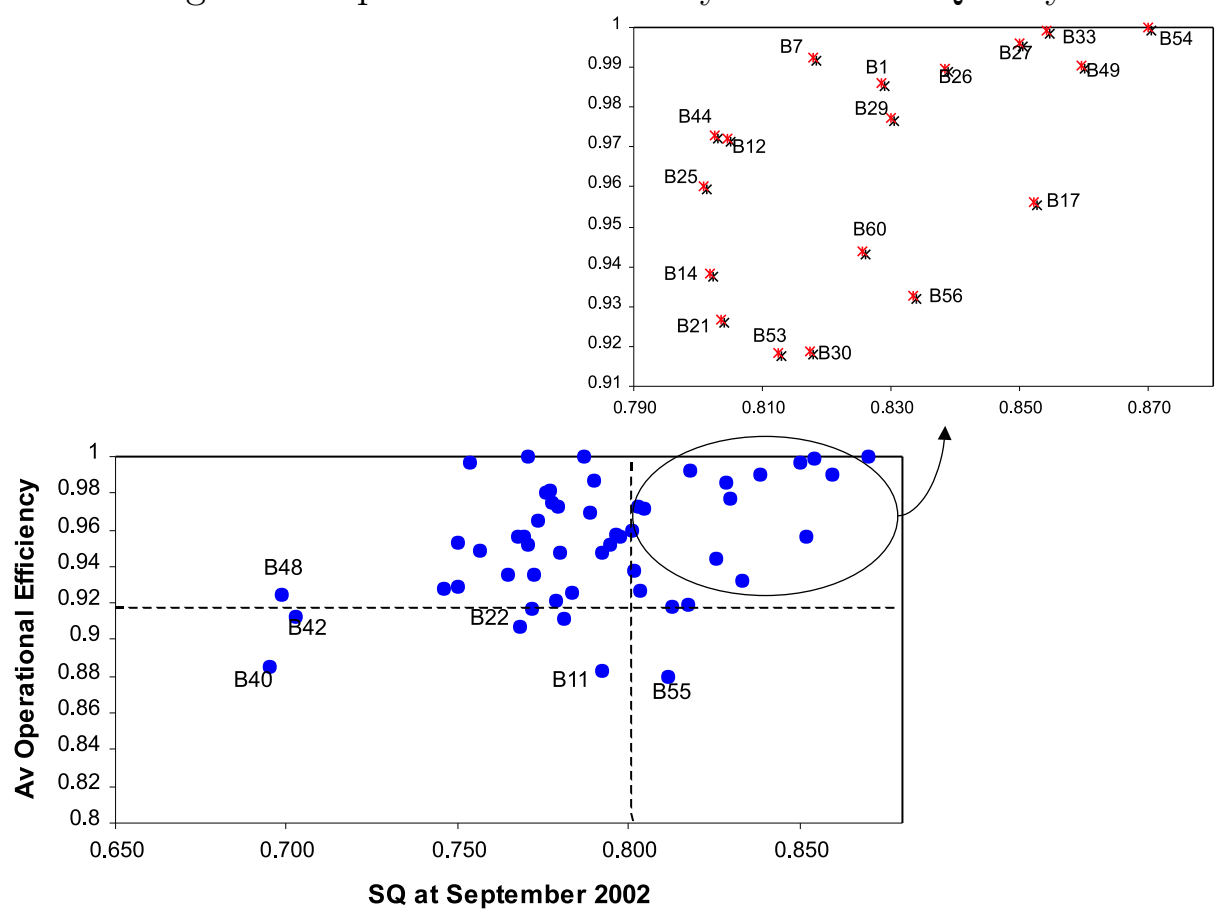

reasonable to assume that a bank branch with a service quality level above this value was performing at high levels of service quality.

Figure 4 shows a positive relationship between operational efficiency and the service quality index. The correlation coefficient is 0.43 and this is significant at the $1 \%$ level. More important than analysing this relationship is, however, the analysis of the bank branches that lie on each of the quadrants identified in Figure 4. It is interesting to note that there are virtually no branches in the quadrant with low operational efficiency and high service 
quality, which obviously is in accordance with the common sense feeling that bank branches providing high service quality are more effective in increasing their customer base and in selling banking products. Star branches in Figure 4 can be seen as benchmarks in operational terms, since they show at the same time high operational efficiency and high service quality. Such branches attain growth rates that are better than those of other branches, while at the same time they tend to serve clients with a better service quality than other bank branches.

Comparing service quality with profit efficiency reveals the picture shown in Figure 5. Here the relationship between service quality and profit efficiency is not as clear as with

Figure 5: Profit Efficiency Vs Service Quality
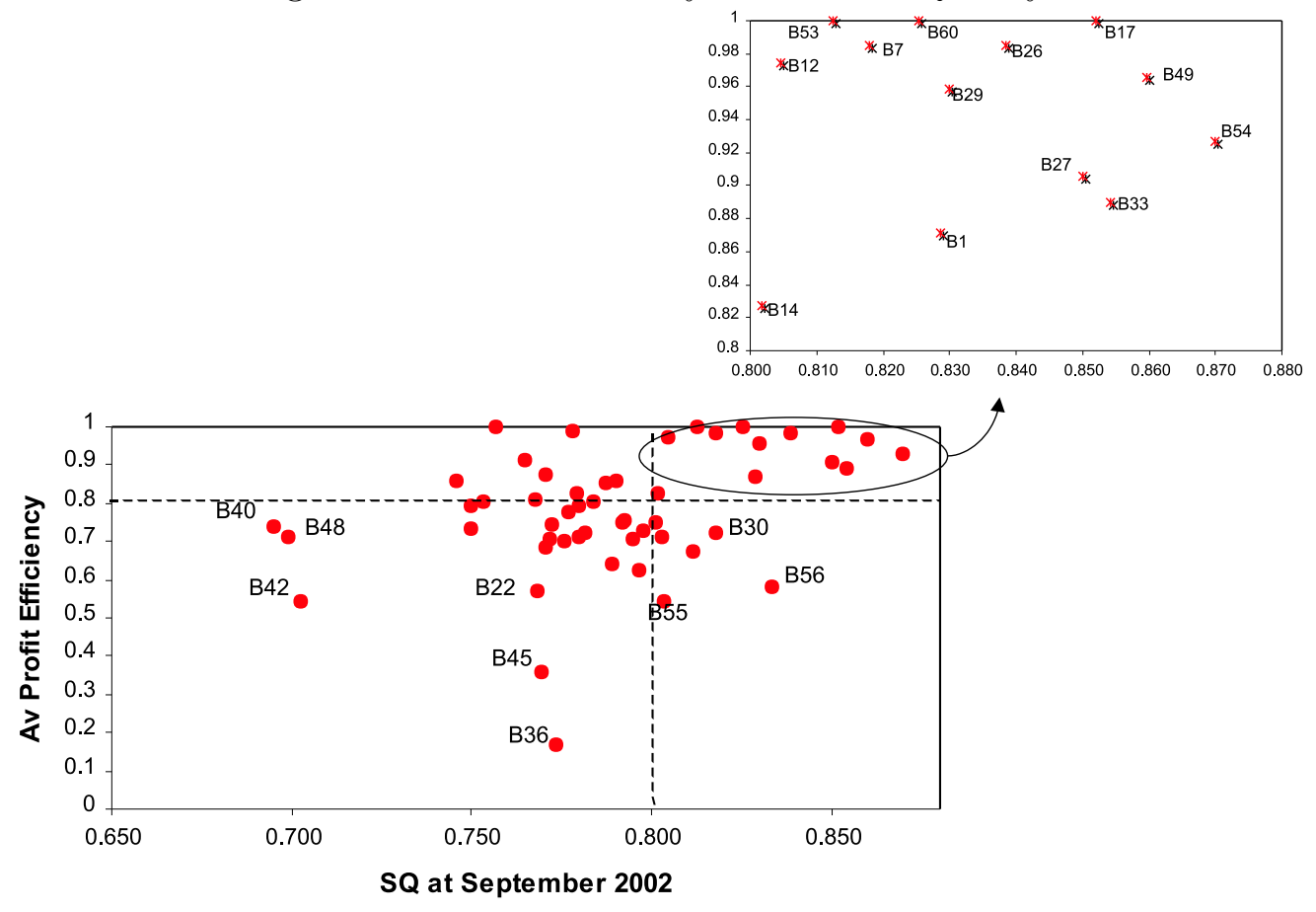

operational efficiency. We can now find some branches in the quadrant with low profit efficiency and high service quality. Nevertheless, there appears to be a positive relationship between profit efficiency and service quality, meaning that higher service bank branches tend to be good performers both in terms of generating profits and in terms of operational growth. In fact the correlation coefficient between service quality and profit efficiency is lower than before (0.371) but this value is still significant at the $1 \%$ level. The weaker relationship 
between profit efficiency and service quality may be due to the lag effect between the costs of quality and the revenues accruing from superior quality that we mentioned before.

The relationship between service quality and transactional efficiency is completely different from those shown before, as there appears to be no relationship between these two performance dimensions. This can be seen in Figure 6 .

Figure 6: Transactional Efficiency Vs Service Quality

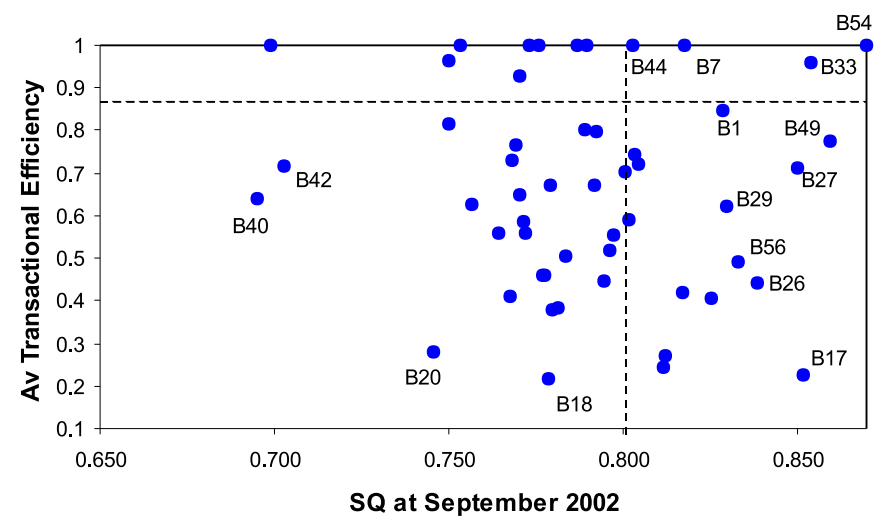

The correlation coefficient between transactional efficiency and service quality is -0.0914 and this value is not statistically significant. This fact seems to suggest that the efficiency by which bank branches move transactions away from the bank branch does not affect service quality. This is an important finding since it means that customers do not associate the increasing use of alternative distribution channels (and the decreasing use of the branch for transactional purposes) with losses in terms of service quality (nor gains).

In order to better understand the implications of cross-comparing the various performance dimensions, we looked at some bank branches and analysed their performance in each dimension. In Figure 7 we show the performance of three bank branches in terms of profit efficiency, operational efficiency, transactional efficiency, and service quality (average values from January 2002 to September 2002). In this Figure it is clear that branches B54, B40 and B17 have different profiles in terms of their performance. B54 is a good performer in all dimensions being considered, while branch B17 shows high performance in all di- 
Figure 7: Performance Profile of three Bank Branches

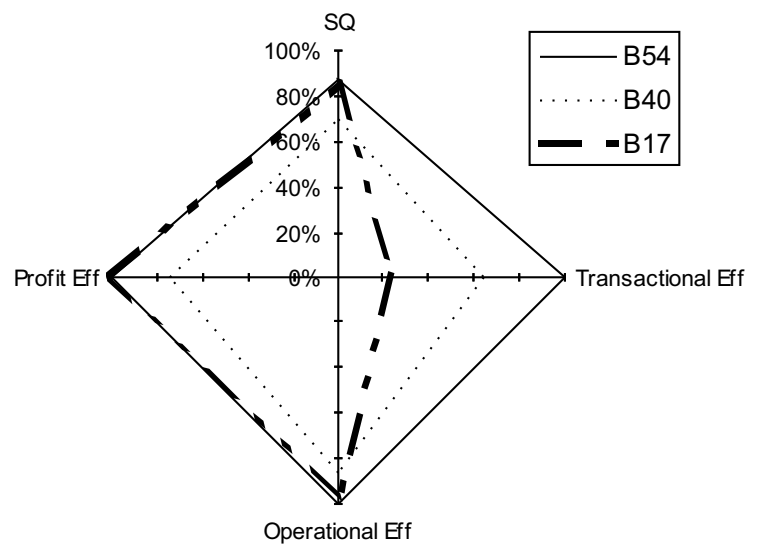

mensions except transactional efficiency, where its performance is problematically low. On the other hand branch B40 presents an average and balanced profile, showing potential for improvement in all the dimensions being considered.

Further investigation on the causes of poor performance can be achieved by a detailed analysis of the actual values of inputs and outputs of the efficiency assessments. This can also be done through the use of radar charts, as seen before. This type of analysis is, however, too detailed to be pursued here.

\section{Consistency of Results with Prior Views of the Bank}

In order to gauge the consistency of our results with the perspective of managers, the results presented here were also shown to the manager of the branch network. In general the network manager agreed with our classifications in all dimensions of performance for almost all the branches. There was, however, more agreement on the identification of the worst performers rather than on the identification of the best performers. For example, the network manager showed no doubts in considering branches B40, B22, and B55 as bad performers and some reasons were pointed out for this, since problems at these bank branches were well known to management. For example, for one of these branches, located in the center of Porto, 
problems related with the use of obsolete technology, with the reluctancy of customers to use other distribution channels, and with the lack of a pro-active attitude of staff towards selling. For another bank branch it was pointed out that this branch received recently several clients from another bank branch that closed, and clients were not satisfied with this change, which was clearly influencing the overall performance of the branch.

As far as best performers are concerned there was less agreement. In some cases the branches we identified as best performers were located in small rural cities and managers did not expected to see these bank branches appearing as best performers. This mainly arises due to the fact that the business volume at these branches is not very high and therefore this type of bank branches is not seen as contributing much to the profits of the bank as a whole (note that contribution to the overall profit of the bank is the main instrument based on which branches are assessed by the bank). Nevertheless the manager accepted most of the branches identified as best performing as indeed performing well.

The fact that managers agreed more with the identification of worst performers can be linked with the fact that DEA by nature makes a stronger identification of weak performers. It tries to show the branch in the best light and if it even then finds it inefficient this means the branch is, more often than not, truly inefficient. This does not hold for efficient branches as they may appear so through an odd combination of input-output levels and lack of similar comparators.

Though we can say that in general agreement was found between our classification of bank branches and prior views of bank managers, it is important to keep in mind that our results only reflect differences between bank branches on the variables that were considered in the efficiency assessments. This means that many reasons may exist for explaining why some bank branches were considered less efficient than others. Such reasons may be due to the variables that were not considered in the assessment, which for some cases might 
be more important than those considered. Apart from this limitation, which is inherent to any quantitative study, we believe that this study indeed captured important performance differences between bank branches and mostly classified them correctly on efficiency. In addition, the relationship identified between the various performance dimensions confirmed our initial expectations regarding the links between them.

\section{Conclusion}

In this paper we developed a novel way to assess the performance of bank branches focusing on three dimensions of performance: transactional, operational and profit. These performance dimensions were the result of linking a set of factors that we wished to account for: (i) The new role of bank branches from transaction-based to sales-based; (ii) The fact that bank branches are service organisations where the measurement of efficiency cannot be disentangled from service quality; (iii) The fact that bank branches are for profit organisations; and (iv) Bank branches' objectives as seen by bank managers.

Performance comparisons on each dimension allowed the identification of benchmark branches and also the identification of problematic branches that need to be looked at carefully. Our results show some interesting links between performance dimensions. Namely, we conclude that transactional efficiency is positively related with operational efficiency and that operational efficiency is positively related with profit efficiency. Service quality is also positively related with profit and operational efficiency but seems to be unaffected by transactional efficiency. Our results were discussed with the network manager and in general our classifications of best and worst performers were considered accurate. 


\section{References}

Athanassopoulos, A. D. (1997). Service quality and operating efficiency synergies for management control in the provision of financial services: Evidence from Greek bank branches. European Journal of Operational Research, 98:300-313.

Athanassopoulos, A. D. (2000). An optimisation framework of the triad; service capabilities, customer satisfaction and performance. In Harker, P. T. and Zenios, S. A., editors, Performance of Financial Institutions; Efficiency, Innovation and Regulation, pages 312-335. Cambridge University Press, Cambridge, UK.

Athanassopoulos, A. D. and Giokas, D. (2000). The use of data envelopment analysis in banking instaitutions: evidence from the commercial bank of Greece. Interfaces, 30(MarchApril):81-95.

Athanassopoulos, A. D., Soteriou, A. C., and Zenios, S. A. (2000). Disentangling within- and between-country efficiency differences of bank branches. In Harker, P. T. and Zenios, S. A., editors, Performance of Financial Institutions; Efficiency, Innovation and Regulation, pages 336-363. Cambridge University Press, Cambridge, UK.

Avkiran, N. K. (1999). An application reference for data envelopment analysis in branch banking: helping the novice researcher. International Journal of Bank Marketing, $17(5): 206-220$.

Banker, R. D. (1996). Hyposthesis tests using data envelopment analysis. Journal of Productivity Analysis, 7:139-159.

Banker, R. D., Charnes, A., and Cooper, W. W. (1984). Some models for estimating technical and scale inefficiencies in data envelopment analysis. Management Science, 30:1078-1092. 
Banker, R. D. and Morey, R. C. (1986). Efficiency analysis for exogenously fixed inputs and outputs,. Operations Research, 34(4):513-520.

Berger, A. N., Hancock, D., and Humphrey, D. B. (1993). Bank efficiency derived from the profit function. Journal of Banking and Finance, 17:314-347.

Berger, A. N., Leusner, J. H., and Mingo, J. J. (1997). The efficiency of bank branches. Journal of Monetary Economics, 40(1):141 - 162.

Boussofiane, A., Dyson, R. G., and Thanassoulis, E. (1991). Applied data envelopment analysis. European Journal of Operational Research, 52(1):1-15.

Camanho, A. S. and Dyson, R. G. (1999). Efficiency, size, benchmarks and targets for bank branches: An application of data envelopment analysis. Journal of the Operational Research Society, 50(9):903-915.

Chambers, R. G., Chung, Y., and Färe, R. (1996). Benefit and distance functions. Journal of Economic Theory, 70:407-419.

Chambers, R. G., Chung, Y., and Färe, R. (1998). Profit, directional distance functions, and Nerlovian efficiency. Journal of Optimization Theory and Applications, 98(2):351-364.

Colwell, R. J. and Davis, E. P. (1992). Output and productivity in banking. Scandinavian Journal of Economics, 94(Supplement):S111-S129.

Cook, W. D. and Hababou, M. (2001). Sales performance measurement in bank branches. Omega, The International Journal of Management Science, 29:299-307.

Cook, W. D., Hababou, M., and Tuenter, H. J. H. (2000). Multicomponent efficiency measurement and shared inputs in data envelopment analysis: an application to sales and service performance in bank branches. Journal of Productivity Analysis, 14:209-224. 
Cooper, W. W., Seiford, L. M., and Tone, K. (2000). Data Envelopment Analysis: A comprehensive text with models, applications, references and DEA-Solver software. Kluwer Academic Publishers, Boston.

Drake, L. and Howcroft, B. (1994). Relative efficiency in the branch network of a UK bank: An empirical study. Omega: The International Journal of Management Science, 22(1):83-90.

Drake, L. and Howcroft, B. (1995). Measuring the relative efficiency of the selling function: An application of data envelopment analysis to UK bank branches. Loughborough University Banking Centre, Working Paper N. 89/95.

ECB (1999a). The effects of technology on the EU banking systems. European Central Bank, July.

ECB (1999b). Possible effects of EMU on the EU banking systems in the medium and long term. European Central Bank, February.

Giokas, D. (1991). Bank branch operating efficiency: A comparative application of DEA and the loglinear model. Omega: The International Journal of Management Science, $19(6): 549-557$.

Golany, B. and Storbeck, J. E. (1999). A data envelopment analysis of the operational efficiency of bank branches. Interfaces, 29(3):14-26.

Grönroos, C. (2000). Service Management and Marketing, a customer relationship management approach. John Wiley and Sons, LTD, second edition.

Hartman, T. E., Storbeck, J. E., and Byrnes, P. (2001). Allocative efficiency in branch banking. European Journal of Operational Research, 134:232-242. 
Howcroft, J. B. (1991). Customer satisfaction in retail banking. Service Industries Journal, 11(1):11-17.

Howcroft, J. B. (1992). Contemporary issues in UK bank delivery systems. International Journal of Service Industry Management, 3(1):39-56.

Howcroft, J. B. and Beckett, A. (1993). Change in the UK bank branch networks: A customer perspective. The Service Industries Journal, 13(4):267-288.

Parkan, C. (1987). Measuring the efficiency of service operations: An application to bank branches. Engeneering Costs and Production Economics, 12:237-242.

Portela, M., Thanassoulis, E., and Simpson, G. (2004). Negative data in DEA: A directional distance approach applied to bank branches. Journal of the Operational Research Society, $55: 1111-1121$.

Portela, M. C. A. S. (2003). New Insights on Measuring Bank Branches Efficiency through DEA: Transactional, Operational, and Profit Assessments. PhD thesis, Aston Business School, Aston University, Birmingham B4 7ET, U.K.

Portela, M. C. A. S. and Thanassoulis, E. (2005). Profitability of a sample of Portuguese bank branches and its decomposition into technical and allocative components. European Journal of Operational Research, 162(3):850-866.

Portela, M. C. S., Borges, P., and Thanassoulis, E. (2003). Finding closest targets in non-oriented DEA models: The case of convex and non-convex technologies. Journal of Productivity Analysis, 19(2/3):251-269.

Schaffnit, C., Rosen, D., and Paradi, J. C. (1997). Best practice analysis of bank bran- 
ches: An application of DEA in a large canadian bank. European Journal of Operational Research, 98:269-289.

Sherman, H. D. and Gold, F. (1985). Bank branch operating efficiency: Evaluation with DEA. Journal of Banking and Finance, 9(2):297-315.

Sherman, H. D. and Ladino, G. (1995). Managing bank productivity using data envelopment analysis (dea). Interfaces, 25(March-April):60-73.

Soteriou, A. and Zenios, S. A. (1999). Operations, quality and profitability in the provision of banking services. Management Science, 45(9):1221-1238.

Thanassoulis, E. (2001). Introduction to the theory and application of Data Envelopment analysis: A foundation text with intefrated software. Kluwer Academic Publishers.

Thanassoulis, E., Boussofiane, A., and Dyson, R. G. (1995). Exploring output quality targets in the provision of perinatal care in England using data envelopment analysis. European Journal of Operational Research, 80:588-607.

Tulkens, H. (1993). On FDH efficiency analysis: Some methodological issues and applications to retail banking, courts and urban transit. Journal of Productivity Analysis, 4:183-210.

Vassiloglou, M. and Giokas, D. (1990). A study of the relative efficiency of bank branches: An application of data envelopment analysis. Journal of Operational Research Society, 41(7):591-597.

Zenios, C. V., Zenios, S. A., Agathocleous, K., and Soteriou, A. C. (1999). Benchmarks of the efficiency of bank branches. Interfaces, 29(3):37-51. 


\section{Appendix}

\section{A Model used in Operational Efficiency Assessment}

Consider a set of units $j=1, \ldots, n$, with input levels $x_{i j}, i=1, \ldots, m$ and output levels $y_{r j}, r=1, \ldots, s$, and unit $o \in j$, which is to be assessed. Define an ideal point as given by $I=\left(I_{y r}, I_{x i}\right)=\left(\max _{j}\left\{y_{r j}\right\}, \min _{j}\left\{x_{i j}\right\}\right)$, and a range of possible improvement for outputs of unit $o$ as given by $R_{r o}=I_{y r}-y_{r o}=\max _{j}\left\{y_{r j}\right\}-y_{r o}, r=1, \ldots, s$. The output oriented Range Directional Model (RDM) is given by (1).

$$
\begin{array}{r}
\max _{\beta_{o}, \lambda_{j}}\left\{\beta_{o} \mid \sum_{j=1}^{n} \lambda_{j} y_{r j} \geq y_{r o}+\beta_{o} R_{r o} \quad r=1, \ldots, s, \quad \sum_{j=1}^{n} \lambda_{j} x_{i j} \leq x_{i o} \quad i=1, \ldots, m\right. \\
\left.\sum_{j=1}^{n} \lambda_{j}=1, \lambda_{j} \geq 0\right\}
\end{array}
$$

Input and output values to be used in the RDM model (1) can be negative, since the RDM model is translation and units invariant (Portela et al., 2004). The efficiency measure reflecting the distance from observed points to its targets (with reference to the ideal point) is directly obtained from (1) as $1-\beta_{o}$.

\section{B Model used in Profit Efficiency Assessment}

Consider a set of units $j=1, \ldots, n$, with input levels $x_{i j}, i=1, \ldots, m$ and output levels $y_{r j}, r=1, \ldots, s$, and unit $o \in j$, which is to be assessed. Output prices are denoted by $p_{r j}$ and input prices are denoted by $w_{i j}$ for each unit $j$.

Overall profit efficiency, and technical profit efficiency are calculated through the Geo-

metric Distance Function (GDF) defined in (2), where $\theta_{i}=\frac{x_{i}^{*}}{x_{i}}, \beta_{r}=\frac{y_{r}^{*}}{y_{r}}$, and $\left(y_{r}^{*}, x_{i}^{*}\right)$ is a 
target vector that can be a maximum profit target or a technical efficient target.

$$
G D F=\frac{\left(\Pi_{i} \theta_{i}\right)^{1 / m}}{\left(\Pi_{r} \beta_{r}\right)^{1 / s}}
$$

Long run maximum profit targets are obtained from the solution of model (3).

$$
\begin{aligned}
\max _{\lambda_{j}, y_{r}, x_{i}}\left\{\sum_{r=1}^{s} p_{\text {ro }} y_{r}-\sum_{i=1}^{m} w_{i o} x_{i} \mid \sum_{j=1}^{n} \lambda_{j} y_{r j}-y_{r} \geq 0 r=1, \ldots, s,\right. \\
\left.\sum_{j=1}^{n} \lambda_{j} x_{i j}-x_{i} \leq 0 \quad i=1, \ldots, m, \sum_{j=1}^{n} \lambda_{j}=1, \lambda_{j} \geq 0, j=1, \ldots, n\right\}
\end{aligned}
$$

Overall profit efficiency is obtained by applying $(2)$, where $\left(y_{r}^{*}, x_{i}^{*}\right)$ are obtained from the optimal solution of (3).

Long run technical efficient targets are obtained from the solution of model (4).

$$
\begin{array}{r}
\mathrm{EFF}_{o}=\min _{\theta, \beta, \lambda_{j}}\left\{\frac{\theta}{\beta} \mid \sum_{j \in E} \lambda_{j} y_{r j} \geq \beta y_{r o}, \sum_{j \in E} \lambda_{j} x_{i j} \leq \theta x_{i o}, \quad \sum_{j \in E} \lambda_{j}=1,\right. \\
\left.\lambda_{j}, \geq 0, \quad 0 \leq \theta \leq 1, \text { and } \beta \geq 1\right\}
\end{array}
$$

The objective function of (4) is a special case of the GDF, where all inputs are contracted in the same proportion and all outputs are expanded in the same proportion. Pareto-efficient targets resulting from model (4) are used in (2) to calculate technical profit efficiency. We assure that Pareto-efficient targets result from the linear combination of the $\lambda_{\mathrm{s}}$ in (4) by restricting the reference set to Pareto-efficient units (units in the set $E$ ).

Note that technical efficient targets to be used in (2) can be calculated through any known procedure. In Portela and Thanassoulis (2005) we used a closest target procedure developed in Portela et al. (2003) to find technical efficient targets that were then used in (2) to calculate technical profit efficiency. We do not use this procedure in this paper to calculate technical 
efficient targets because the closest target procedure is time and computational expensive. Therefore, a more practical procedure was needed for calculating technical efficient targets for a number of months.

Allocative efficiency can be found by decomposition since Overall Profit Efficiency = Technical Profit Efficiency $\times$ Allocative Profit Efficiency, or it can be directly obtained from the GDF in (2). Considering a technically profit efficient point $\left(\mathbf{x}^{\prime}, \mathbf{y}^{\prime}\right)$ and a maximum profit point $\left(\mathbf{x}^{*}, \mathbf{y}^{*}\right)$, then the GDF allocative profit efficiency is given by $\frac{\left(\Pi_{i} \frac{x_{i}^{*}}{x_{i}^{i}}\right)^{1 / m}}{\left(\Pi_{r} \frac{y_{r}^{*}}{y_{r}^{\prime}}\right)^{1 / s}}$. 